\title{
Titanium-Nickel Shape Memory Alloy Spring Actuator for Forward-Looking Active Catheter
}

\author{
Takahiro Namazu, ${ }^{1}$ Mamoru Komatsubara, ${ }^{1}$ Hiroyuki Nagasawa, ${ }^{2}$ Takahiro Miki, ${ }^{2}$ \\ Takafumi Tsurui, ${ }^{2}$ and Shozo Inoue ${ }^{1}$ \\ ${ }^{1}$ Division of Mechanical Systems, Department of Mechanical and Systems Engineering, University of Hyogo, 2167 Shosha, Himeji, \\ Hyogo 671-2201, Japan \\ ${ }^{2}$ New Business Department, Kobe Material Testing Laboratory, 47-13 Niijima, Harima, Kako, Hyogo 675-0155, Japan
}

Correspondence should be addressed to Takahiro Namazu, namazu@eng.u-hyogo.ac.jp

Received 1 April 2010; Revised 7 December 2010; Accepted 9 January 2011

Academic Editor: Brij Kumar Dhindaw

Copyright ( $) 2011$ Takahiro Namazu et al. This is an open access article distributed under the Creative Commons Attribution License, which permits unrestricted use, distribution, and reproduction in any medium, provided the original work is properly cited.

The fabrication and characterization of forward-looking active catheter actuated by titanium-nickel (Ti-Ni) shape memory alloy (SMA) springs are described. The catheter has been designed for wide-range observation of an affected area inside a blood vessel when the blood vessel is occluded. The developed active catheter consists of eight Ti-Ni SMA spring actuators for actuation of catheter tip, an ultrasonic transducer for forward-looking, a guide wire, a polyurethane tube for coating, and spiral wirings for realization of various flexure motions of catheter tip using Ti-Ni SMA actuators. The size of the catheter is $3.5 \mathrm{~mm}$ in diameter and $60 \mathrm{~mm}$ in length of the sum of transducer and actuator sections. Ti-Ni SMA springs were fabricated from a Ti-50.9at.\%Ni sheet by electrochemical etching with a mixed solution of ethanol and lithium chloride. The catheter was assembled by hand under a stereomicroscope. The tip of the produced catheter was able to move in parallel toward at least eight directions by controlling an applied current to Ti-Ni SMA springs. We have confirmed that the active catheter was able to observe an object settled in the front.

\section{Introduction}

In the medical field, the catheter is a promising tool and can be widely used for minimally invasive treatment. To date, many kinds of catheter have come into practical use to remedy inside the blood vessel. To accurately treat a diseased area inside a blood vessel using a catheter, doctors must examine the exact condition of the area. It is, however, difficult to do that because doctors have to control a catheter from the outside of patient body. At present, doctors need to manipulate the catheter with their sense and experience when a blood vessel is completely occluded. So, there is some risk for catheter remedy that doctors may harm a nondiseased area accidentally. To address this issue, several devices have been developed for observing the inside of blood vessel [1-6]. For instance, intravascular ultrasound (IVUS) having a number of transducers around the catheter tube is able to obtain the cross sectional image of a blood vessel [6]. However, the device is hard to be used if the blood vessel is blocked up by a thrombus. Furthermore, even if the thrombus in front of the catheter is observed, there is no much obtainable information. Thus, a novel technique for examining a thrombus in front of the catheter should be developed for more definitive treatment.

The purpose of this study is to develop a forwardlooking active catheter for observing a diseased area, such as thrombus, inside a blood vessel. The catheter has an ultrasonic transducer at the catheter tip for observing its front and eight Ti-Ni SMA actuators around the catheter tube for actuating the catheter tip in several directions. Ti-Ni SMA was employed for the actuation source since Ti-Ni SMA that is biocompatible material yields large force output per unit volume [7-14]. We have produced the active catheter and have investigated the possibility for practical treatment by conducting several basic actuation tests.

\section{Device Concept}

Figure 1 illustrates a concept of the forward-looking active catheter. The designed catheter has an ultrasonic transducer 


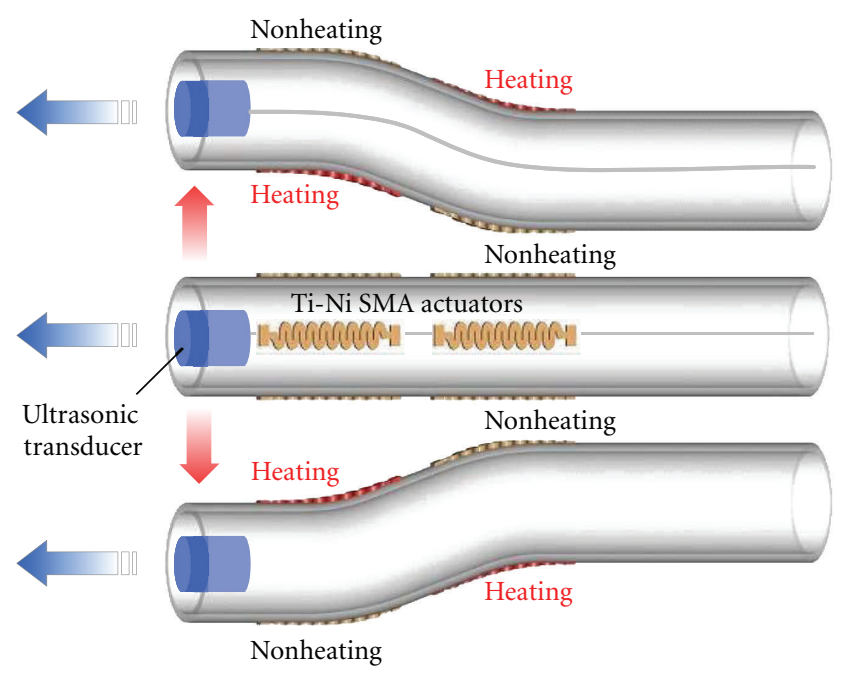

FIGURE 1: Schematic diagram of a concept of the forward-looking active microcatheter.

at the tip of the catheter for observing its front, and eight Ti-Ni SMA zigzag-shaped spring actuators around a catheter tube for bending catheter tip. The zigzag shape has been adopted for large outputs of recovery force and displacement from the actuator. The zigzag spring SMA actuators, which are in a martensitic phase in ambient air temperature, are tensioned by external load, and only both the ends are fixed onto the catheter tube using a conductive paste. Then, by Joule's heating, SMA actuators are transformed from the martensitic into the austenitic phase, so each tensioned actuator can shrink to the memorized shape. If only one SMA actuator is heated, the catheter tube can be bent to the actuation direction because of the reverse transformation. By cutting off the current, the shape of the catheter returns to its initial shape because of elastic recovery force from the catheter tube. The combination of a current application to the Ti-Ni SMA actuators enables the catheter to be bent toward at least the eight directions with an arbitrary angle. In this case, however, the catheter tip is bent with a certain angle, which makes the transducer observation difficult. If two SMA actuators which are fixed in diagonally opposite positions are simultaneously heated, the tip of the catheter can move in parallel without changing the tip angle. So observing a diseased area in front of the catheter becomes possible. Furthermore, using this catheter, a wide-range vision is obtainable by changing the combination of spring actuators that are used.

\section{TI-NI SMA Spring Actuator}

3.1. Fabrication. Figure 2 shows a chart of fabrication process for Ti-Ni SMA spring actuator. The process is classified broadly into five steps. At first, the surface of a Ti-50.9at.\%Ni sheet that has the thickness of $200 \mu \mathrm{m}$ is carefully buffed to remove an oxidation layer that disturbs Ti-Ni sheet etching (step 1). Then, Ni electroplating is conducted on the backside of the sheet (step 2). Ni layer of $20 \mu \mathrm{m}$ in thickness is formed as an etch-stop layer for the electrochemical etching of the sheet. The Ni layer avoids a current crowding effect during the etching. Photolithography is then carried out to form zigzag spring-like structures on Ti-Ni surface as an etching mask (step 3). In this step, the photoresist of a positive type is hard-baked at $473 \mathrm{~K}$ for 1.5 hours to improve chemical tolerance during electrochemical etching. After that, the Ti$\mathrm{Ni}$ sheet is etched with a mixed solution of ethanol and lithium chloride to form a zigzag spring shape (step 4). In this process, the SMA sheet and a stainless plate are respectively set as anode and cathode electrodes, and electrochemical etching is performed by applying a voltage of $10 \mathrm{~V}$ to the electrodes. The photoresist is then removed with a mixed solution of sulfuric acid and hydrogen peroxide solution at $363 \mathrm{~K}$ for 10 minutes. The Ni layer on the backside is finally removed with $\mathrm{Ni}$ etchant at $343 \mathrm{~K}$ for 3 hours. From these processes, the stand-alone Ti-Ni SMA spring structure can be prepared.

Figure 3 shows the snapshots of the etched surface of the Ti-Ni SMA sheet by electrochemical etching. We have consulted the etching conditions described in the reference paper to achieve $\mathrm{Ti}-\mathrm{Ni}$ sheet fabrication precisely [10]. It appears that the side etching has proceeded because the spring width was getting narrow. After 40 minutes, some penetrating holes were observed on the etched surface. This indicates that the etching proceeded to Ni layer. The etching mask of photoresist had a tolerance enough to etch the TiNi SMA layer of $90 \mu \mathrm{m}$. The dimension of fabricated SMA spring actuator was $1 \mathrm{~mm}$ in width, $16 \mathrm{~mm}$ in length, and 70$90 \mu \mathrm{m}$ in thickness. Although the designed width of spring line was $300 \mu \mathrm{m}$, the measured width was $200 \mu \mathrm{m}$ due to side etching. A spring shape of Ti-Ni was successfully formed without any fatal damages. The electrochemical etching with an etch-stop layer of $\mathrm{Ni}$ is effective for forming a Ti-Ni microstructure.

3.2. Actuation Test. The catheter is driven by using the shape memory effect of the fabricated Ti-Ni SMA spring actuators. We have conducted a uniaxial tensile test of the actuators in order to obtain their performances. The specially developed uniaxial tensile tester for SMA characterization was employed, as shown in Figure 4(a). The tester consists of a specimen holder for mechanically fixating the Ti-Ni actuator, a load cell for measuring the applied dead load, a cross roller guide with very low friction, and a loading tank. Putting a weight in the tank produces a horizontal uniaxial tensile force to the specimen. Also, a current can be applied to the fixed actuator via electrodes attached on the specimen holder. Figure 4(b) shows the Ti-Ni SMA actuator fixed on the specimen holder. By applying the uniaxial tensile load of 70 grams to the fixed actuator, the displacement of $1 \mathrm{~mm}$ indicating in elastic deformation range of Ti-Ni was produced, as shown in Figure 4(c). Then, by applying a constant current of $445 \mathrm{~mA}$ to the actuator, the displacement decreased to $0.3 \mathrm{~mm}$, as shown in Figure $4(\mathrm{~d})$. So, the recovered displacement was calculated to be $0.7 \mathrm{~mm}$, which was approximately $70 \%$ of the initial displacement. 


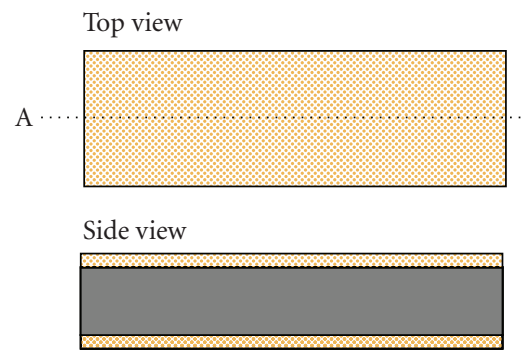

(a) Ti-Ni SMA sheetNi

B

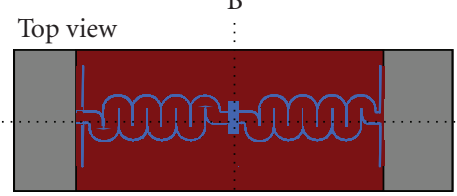

$\mathrm{B}^{\prime}$

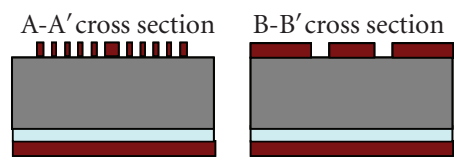

$\square$ Oxide film $\square$ Ti-Ni SMA

$\square \mathrm{Ni}$ Photoresist

(d) Coating and patternning of photoresisitBB
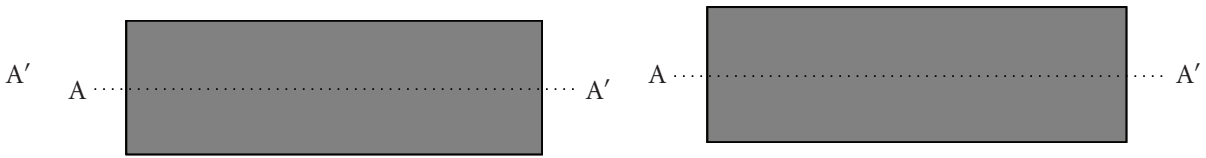

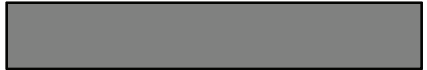

(b) Surface buffingA

B

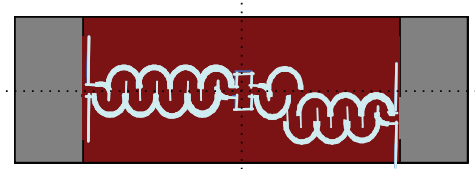

$\mathrm{B}^{\prime}$
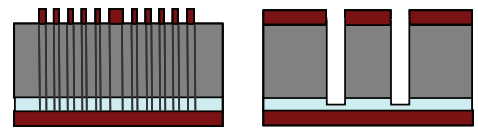

Oxide film

$\square \mathrm{Ni}$

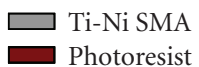

(e) Electrochemical etching of Ti-Ni

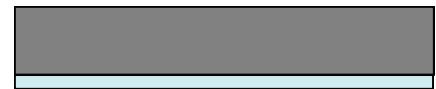

(c) Electroplating of $\mathrm{Ni}$

B

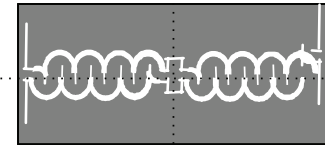

$\mathrm{B}^{\prime}$

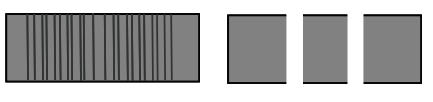

$\square$ Oxide film $\square$ Ti-Ni SMA$$
\text { (f) Etching of photoresist and } \mathrm{Ni}
$$

(f) Etching of photoresist and $\mathrm{Ni}$

Figure 2: Fabrication process of Ti-Ni SMA spring actuator.

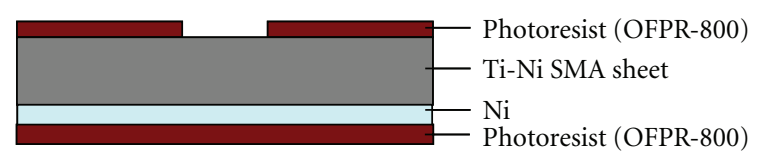

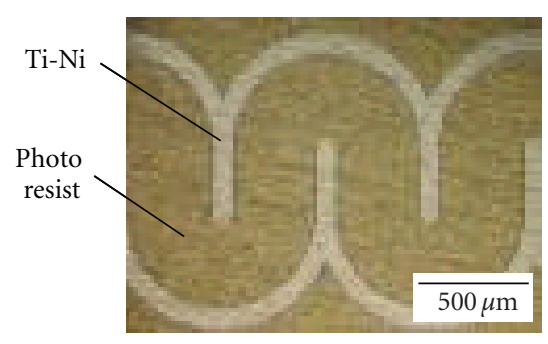

$0 \mathrm{~min}$

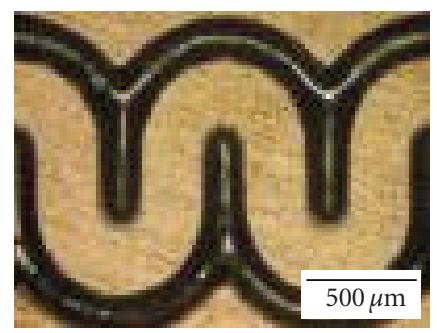

$30 \mathrm{~min}$

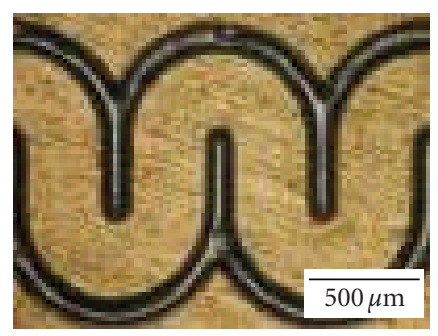

$10 \mathrm{~min}$

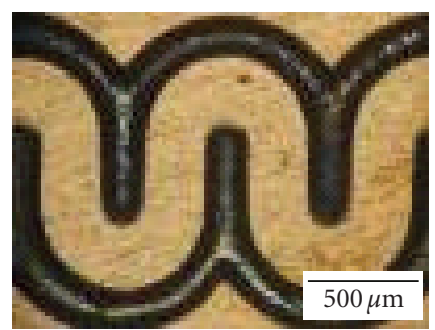

$40 \mathrm{~min}$

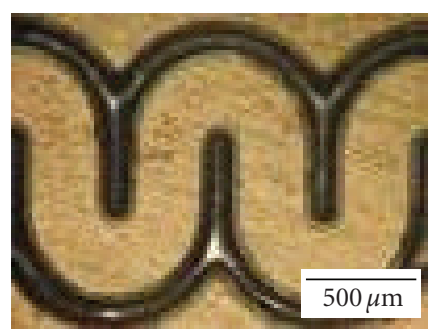

$20 \mathrm{~min}$

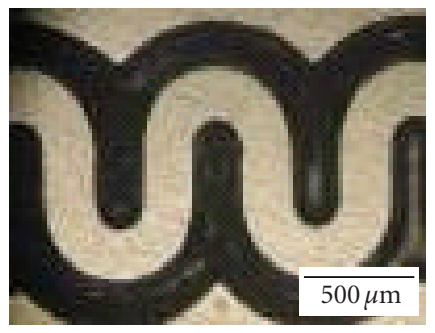

$\mathrm{Ni}$ and photoresist removal

Figure 3: Snapshots of electrochemical etching for Ti-Ni. 

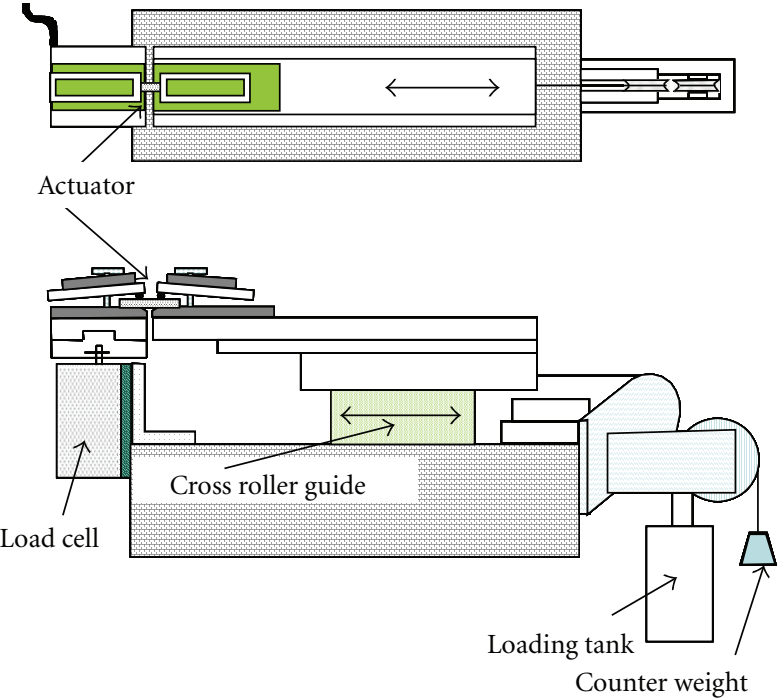

(a)

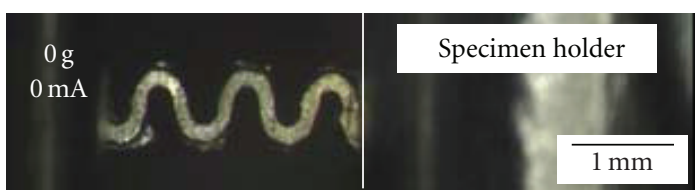

(b)

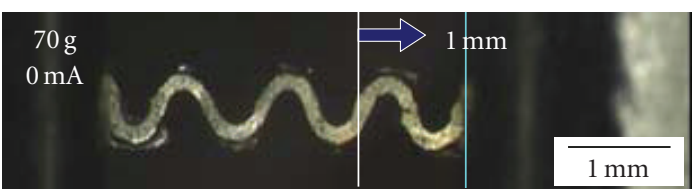

(c)

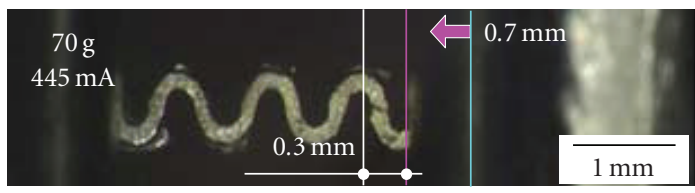

(d)

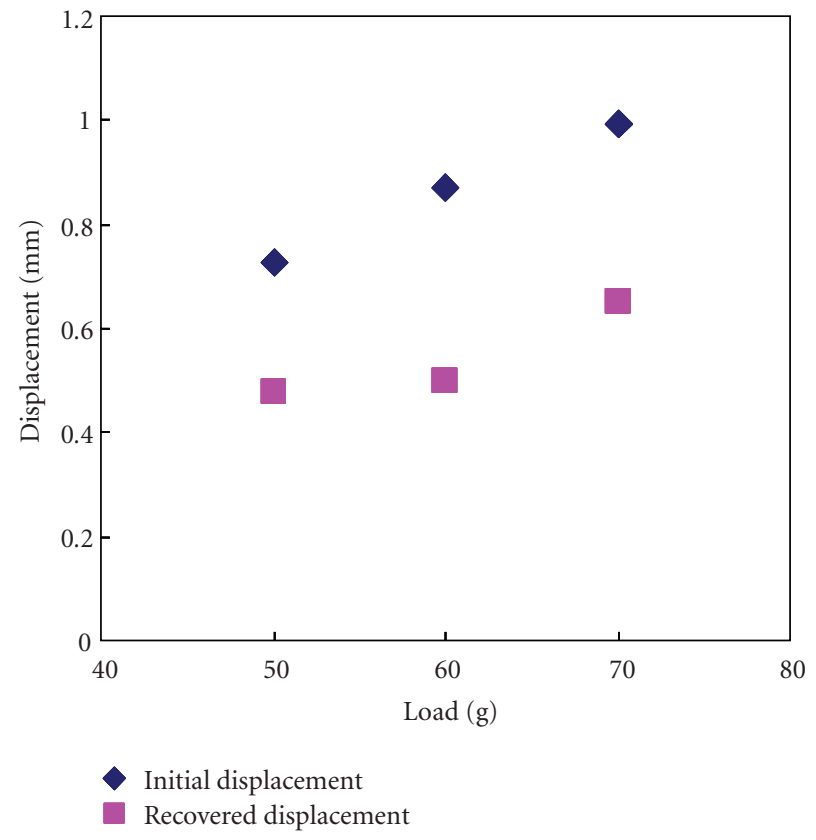

(e)

Figure 4: Ti-Ni SMA actuation test. (a) Schematic of tensile tester for stretching and electrically heating the Ti-Ni SMA spring actuator; (b) actuator fixed on the specimen holder; (c) actuator tensioned by a load of 70 grams; (d) actuator electrically heated with a current of $445 \mathrm{~mA}$; (e) relations between load and displacements.

Figure 4(e) shows the relationships between the applied load, initial, and recovered displacements. The displacements were obtained when a constant current of $445 \mathrm{~mA}$ was applied to the stretched Ti-Ni SMA springs. The initial displacement increased with increasing the applied load. At the applied load of 50 grams, the initial displacement was $0.73 \mathrm{~mm}$. When the load was increased to 70 grams, the displacement increased to $1 \mathrm{~mm}$. The increment ratio of the displacement was calculated to be $13.5 \mu \mathrm{m} / \mathrm{g}$. The recovered displacement at the applied load of 50 grams was $0.48 \mathrm{~mm}$, which increased with the increment of the initial displacement. However, at 50, 60, and 70 grams, the unrecovered displacements of $0.28,0.37$, and $0.34 \mathrm{~mm}$ existed. This might be caused by plastic deformation in TiNi SMA.

Since SMA actuator moves by its phase transformation, the degradation of actuation performance becomes a technical issue to be investigated. We evaluated long-term reliability of Ti-Ni SMA by means of heating/cooling cyclic test under uniaxial tensile load [15]. When a constant tensile load and a 
(1) Catheter tube adoption

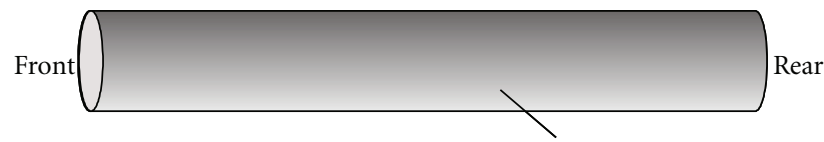

(2) Wiring on the catheter tube $\phi=2.5 \mathrm{~mm}$ double lumen tube

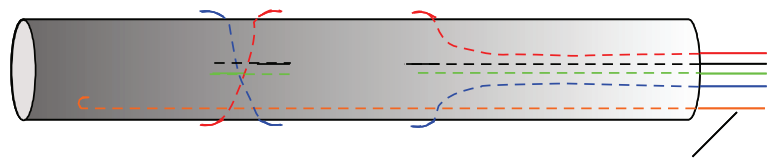

(3) Aluminum film attachment

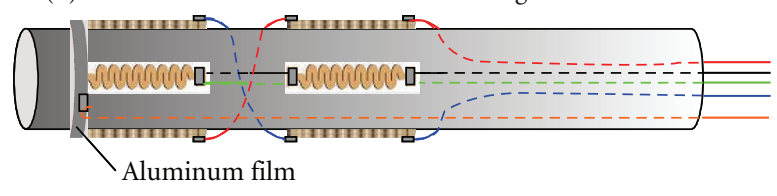

(4) Transducer attachment and surface coating

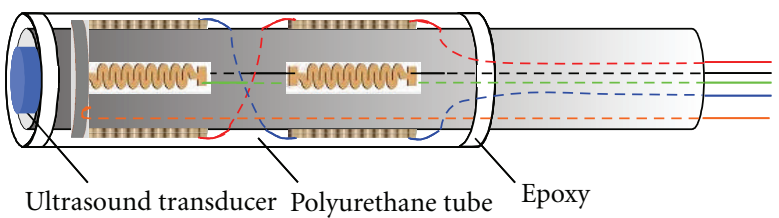

FIGURE 5: Fabrication process of the forward-looking active catheter.

pulse voltage frequency of $10 \mathrm{~Hz}$ were applied, the amplitude did not change during the test up to 1.6 million cycles. This indicates that the SMA springs showed no degradation by cycling martensitic and reverse transformations. Therefore, Ti-Ni SMA springs used for the catheter would be durable to cyclic motion.

\section{Active Catheter}

4.1. Fabrication. Figure 5 shows a process chart for fabricating the forward-looking active catheter. A flexible polyethylene double lumen tube of $2.5 \mathrm{~mm}$ in diameter and $1 \mathrm{~m}$ in length has been adopted since a guide wire has to be used. To electrically connect Ti-Ni SMA actuators in diagonally opposite positions, spiral wiring with a single-core cable was firstly fabricated. After that, eight Ti-Ni SMA actuators that were tensioned by $3 \mathrm{~mm}$ were attached onto the catheter tube with a polyacrylate adhesive and then connected with the single-core cable using conductive polymer paste. The double lumen catheter tube has an elliptical inside tube of $0.8 \mathrm{~mm}$ in diameter, in order to lead a guide wire to the inside tube. The four actuators in the tip side have been connected using aluminum film, so a current can be applied to each pair of actuators independently. Then, the $20 \mathrm{MHz}$ ultrasonic transducer having the diameter of $1 \mathrm{~mm}$ was fixed using an epoxy resin to the catheter tip. The surface of the catheter was finally covered with polyurethane tube which outside diameter, and thickness was $3.5 \mathrm{~mm}$ and $200 \mu \mathrm{m}$, respectively, to avoid a contact between SMA springs and a blood vessel, directly.

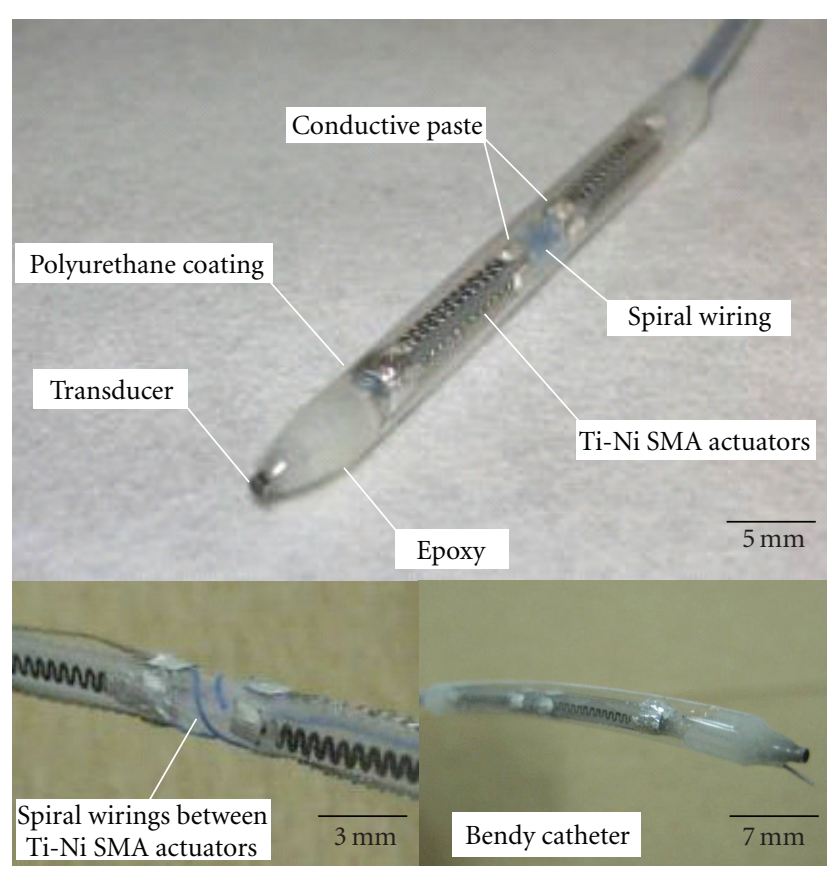

FIGURE 6: Fabricated active catheter with eight Ti-Ni actuators and an ultrasonic transducer.

Figure 6 shows the manufactured active catheter. The catheter is composed of eight Ti-Ni SMA actuators, an ultrasonic transducer, wirings, and a catheter tube. For the practical use, all the wirings go through inside the catheter tube. The spiral wiring enables the catheter tip to move in parallel for forward-looking with ultrasonic transducer. The dimension of the catheter which is the sum of transducer and actuator sections is $3.5 \mathrm{~mm}$ in diameter and $60 \mathrm{~mm}$ in length. The catheter that has good characteristics, such as bendy and biomedical, can be actuated to several directions.

4.2. Actuation Test. We have conducted the actuation test of the manufactured active catheters. The actuation test system employed for the test consists of a current supply for applying constant current to the actuators, a multimeter for measuring a current applied to actuator, and a CCD camera for observing the catheter motion. The motion of the catheter tip was observed when a current of $300 \mathrm{~mA}$ was applied for 1 second.

Figure 7(a) shows the snapshots of the tip of the prototype catheter when applying the current to only one SMA actuator among eight actuators. The catheter tip was bent by 3 degrees to intended directions by using the fabricated Ti-Ni SMA spring actuator. However, the angle possibly gives rise to the difficulty in observing the front side of the catheter by using an ultrasonic transducer. In addition, the catheter may skin the inside wall of a blood vessel because of the generation of the angle in operation, so that the motion would not be suitable for the practical use. On the other hand, as seen in Figure 7(b), when a pair of 


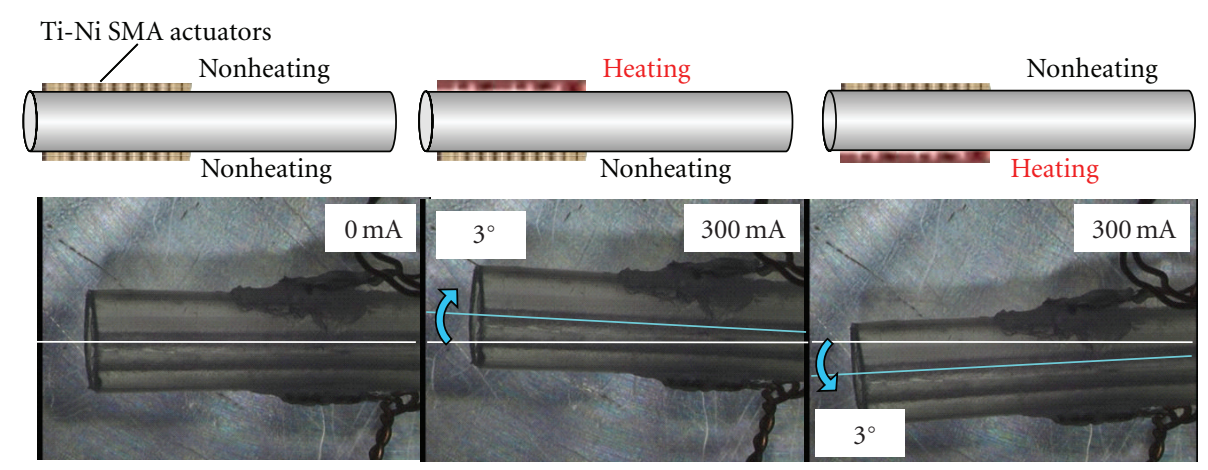

(a)

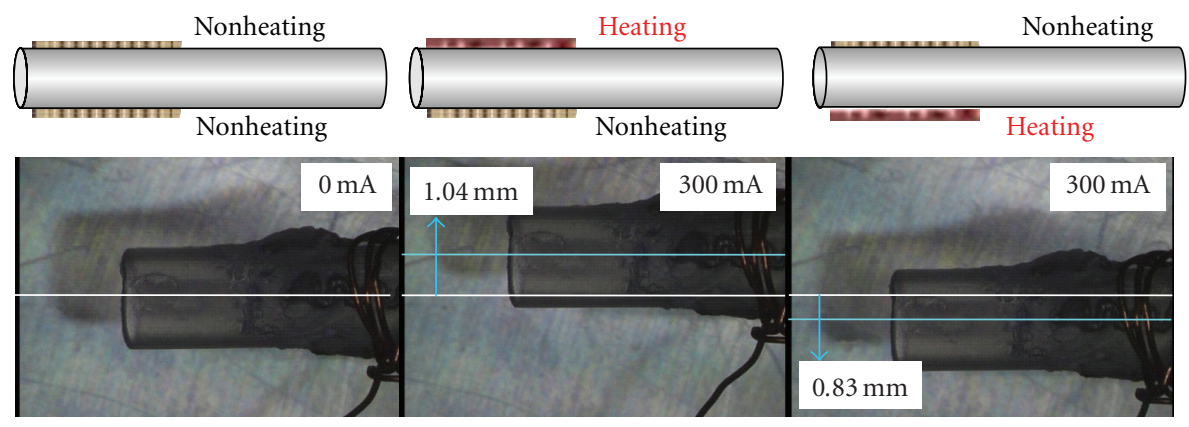

(b)

FIgURE 7: Snapshot of the catheter tip before and after applying the current of $300 \mathrm{~mA}$ to (a) only one actuator and (b) a pair of actuators.

actuators was driven at the same time, the catheter tip moved in parallel. The displacements were found to be 1.04 and $0.83 \mathrm{~mm}$ to intended directions. The reason why the amount of displacements differed in each direction would be the individual difference in shape among actuators. In the case that a pair of actuators was driven, the displacement of the catheter tip was bigger than that in one actuator motion. We confirmed that the actuators were able to generate a recovering force enough to bend the catheter.

As the parallel movement of the catheter tip was observed from the side view of the catheter, the multidirectional movements of the catheter were observed from the front face. Figure 8(a) shows representative actuation test results of the active catheter. When a current of $300 \mathrm{~mA}$ for 1 second was applied to right-front and left-rear actuators, the catheter tip was bent to the upper left direction by $620 \mu \mathrm{m}$. This is a similar value when the current was applied to bottom-front and up-rear actuators. In applying the current to right-front and left-rear actuators together with bottom-front and uprear ones, the catheter tip was bent to the upper left side by $320 \mu \mathrm{m}$, smaller value as compared with the displacements when the catheter tip moved to the up and left sides. This is because the actuation direction was 45 degrees from the up and left sides. In the opposite side, almost the same trend was observed. Thus, the catheter tip was able to be moved in several directions.

On the other hand, the mean actuation speed was estimated to be ranging from 5.2 to $10.3 \mu \mathrm{m} / \mathrm{s}$, which was different among actuation directions. The real-time speed changed during actuation because the actuation of catheter was probably affected by several things, such as SMA's transformation temperature, thermal expansion coefficient, and catheter tube's stress relaxation; therefore, in future, real time monitoring of the displacement of the catheter's tip should be performed to evaluate real actuation speed of the catheter. Moreover, rapid actuation of catheter tip is very important for accurate and quick remedy. To improve the actuation speed of SMA, higher transformation temperatures are required. This is because, for SMA actuator used in ambient temperature, a large difference between transformation temperatures and ambient temperature gives rise to fast cooling speed; consequently quick actuation can be realized. Ternary $\mathrm{Ti}-\mathrm{Ni}$ materials, such as Ti-Ni$\mathrm{Cu}$ and $\mathrm{Ti}-\mathrm{Ni}-\mathrm{Zr}$, have higher transformation temperatures compared with Ti-Ni [16]; therefore, those ternary SMAs would become a strong candidate as actuation materials for the SMA drive catheter producing quick actuation.

Figure 8(b) shows the relationship between the applied current and the displacement. Regardless of the bending directions, the displacement increased with an increase in the applied current from 100 to $400 \mathrm{~mA}$. However, the displacement values in each drive direction were different due to the individual difference in shape among actuators. In the cases of the up and left directions, the displacement did not change in applying $500 \mathrm{~mA}$. The employed Ti-Ni SMA sheet starts to transform into the austenite phase at $312.7 \mathrm{~K}$ ( $A_{\mathrm{S}}$ temperature), and the transformation finishes at $325.1 \mathrm{~K}$ ( $A_{\mathrm{f}}$ temperature). At $400 \mathrm{~mA}$, temperature of the 


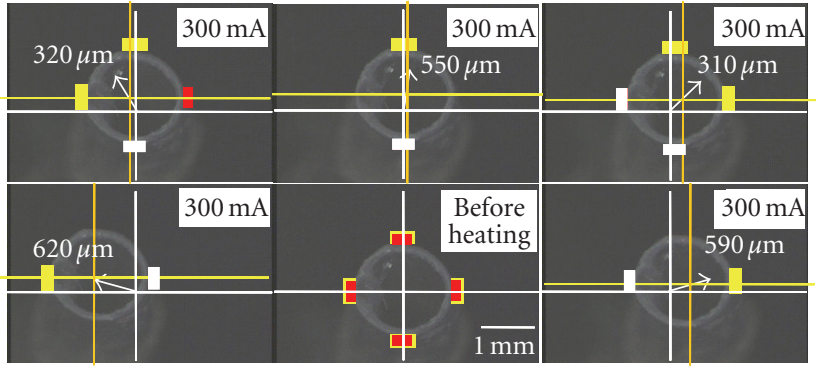

$\square$ Front-actuator

$\square$ Rear-actuator

(a)

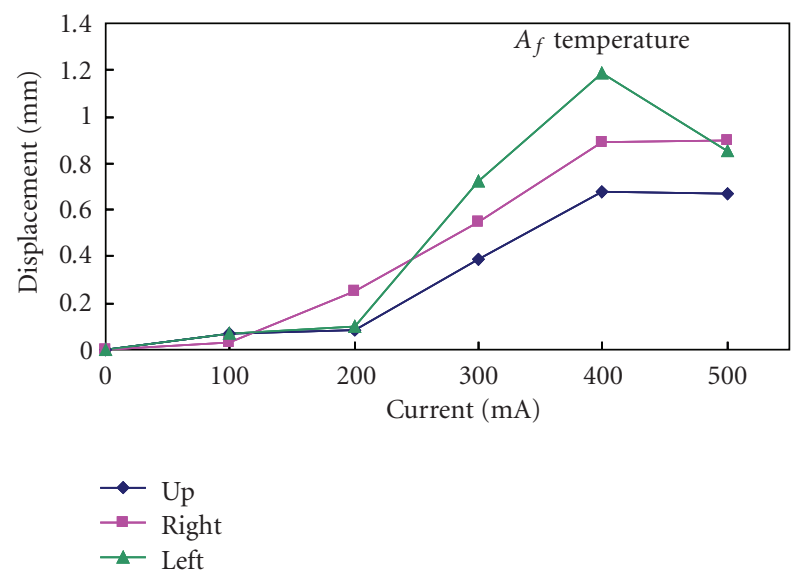

(b)

FIgURE 8: Actuation test results of the forward-looking active catheter: (a) snapshots of the catheter tip driven in five directions by applying current of $300 \mathrm{~mA}$ to several actuators; (b) the relationship between the applied current and resultant displacement.

Ti-Ni SMA spring was thought to be over $325.1 \mathrm{~K}$, and the reverse transformation had finished already. On the other hand, between 400 and $500 \mathrm{~mA}$, the displacement in the right direction reduced. This would be caused by an excessive increase in temperature. The shape of the catheter tube was a little bit distorted by the Joule's heat. Although the displacements were different in each direction, they could be controlled by changing the current.

The actuation tests which results were shown in Figure 8 were successively performed in five cycles, and the mean values in respective moving directions were described. Repeatability in displacement of the catheter tip was approximately $\pm 6 \%$, which is the best value among the three catheters that we have manufactured. The repeatability performance was different by $5.2 \%$ at the maximum among those catheters because we assembled them by hand. The individual differences, such as soldering condition and SMA actuator shape, among the catheters probably gave rise to difference in the actuation performance.

A concentric circle pattern, which has circle intervals of $250 \mu \mathrm{m}$, was observed with a fiberscope attached at the tip of the catheter, instead of the transducer, in order to investigate catheter motion in more detail. Figure 9 shows the obtained forward circle images. The employed fiberscope is $0.9 \mathrm{~mm}$ in diameter. The current of $300 \mathrm{~mA}$ was applied to the catheter to move in left, up, and right direction. When the catheter was actuated toward the up and right sides, the displacements were estimated to be $270 \mu \mathrm{m}$ in both the directions. In the left side actuation, the catheter moved by $190 \mu \mathrm{m}$, which was smaller by $90 \mu \mathrm{m}$ than the displacements in other directions. Furthermore, all the measured displacements with a fiberscope were smaller than those with a CCD camera shown in Figure 8(a). This is because the fiberscope employed was stiffer than the catheter tube. It was confirmed that the fabricated catheter was able to enlarge the observation range.

In operation, surrounding temperature is sure to be above room temperature when the catheter is used in vivo. As the actuator is driven by heating, the temperature difference may affect the motion of the catheter. We have conducted the actuation tests in room air temperature and warm water. Figure 10 show the actuation test results conducted at (a) room temperature in air and (b) $310 \mathrm{~K}$ in warm water. During the test, applied current was controlled in the range from 300 to $415 \mathrm{~mA}$, in order to produce the displacement of around $0.5 \mathrm{~mm}$. The actuation test was conducted three times per one direction. In Figure 10(a), when the current of $415 \mathrm{~mA}$ was applied to right-front and left-rear actuators in air, the catheter tip moved to the left by $0.6 \mathrm{~mm}$. When applying $380 \mathrm{~mA}$ to bottom-front and top-rear actuators, the catheter tip moved to the upward by $0.5 \mathrm{~mm}$. The difference in applied current that was calculated to be $115 \mathrm{~mA}$ is probably caused by that in shape among actuators. These motions were found to be repeatable. In Figure 10(b), the actuation test in warm water was conducted likewise in air, that is, the same currents were applied to the same pairs of actuators. In all the directions, the displacements of the catheter in warm water were almost the same as those in room air. This would be caused by the polyurethane tube covering the catheter tube. The tube prevented the actuator's contact with water and also prevented the thermal exchange between the actuator and water. The environmental condition within this experiment did not affect the catheter motion.

From the experiments performed in this study, the catheter successfully moved in several directions, and the obtainable image was enlarged by the actuation. However, the individual differences in actuation performance between catheters were found. This is because the shape and size of the catheters that were assembled by hand were individually different. In future, the differences should be reduced through the improvements of the accuracies of SMA etching and catheter assembling. In addition, the diameter of the produced catheter described in this paper was $3.5 \mathrm{~mm}$, which was not so small compared with the inside diameter of a blood vessel. To improve the usefulness of the proposed catheter, the catheter's diameter should be designed and manufactured as small as possible. Also, actuation performances, such as actuation speed, repeatability, and reliability, should be evaluated in more detail. Those investigations would be significant to understand the effectiveness of the active catheter. 


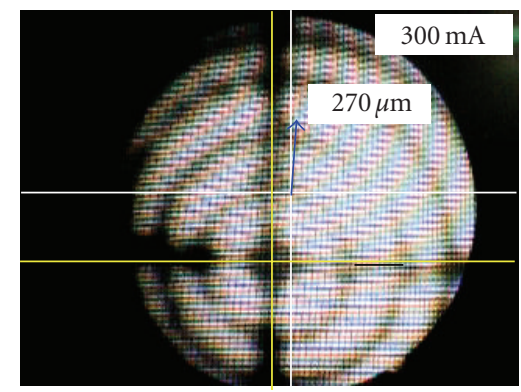

(a)

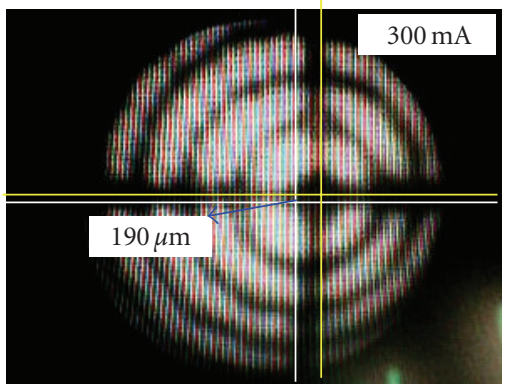

(b)

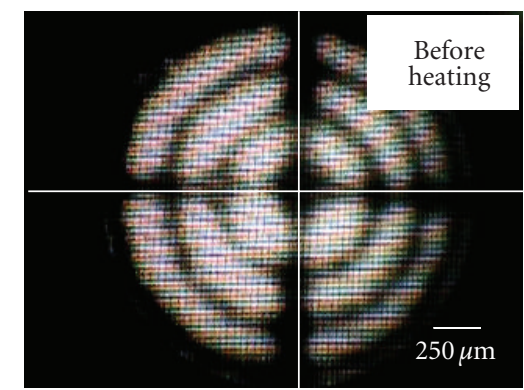

(c)

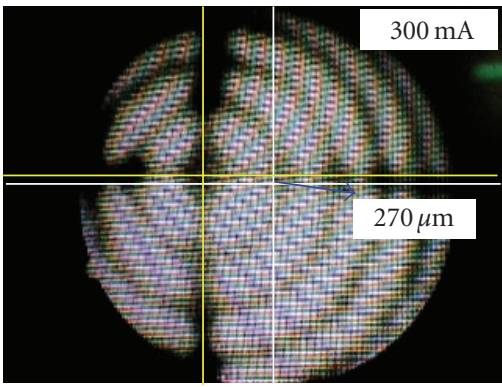

(d)

FIGURE 9: Obtained forward images of the active catheter by moving the tip of catheter.

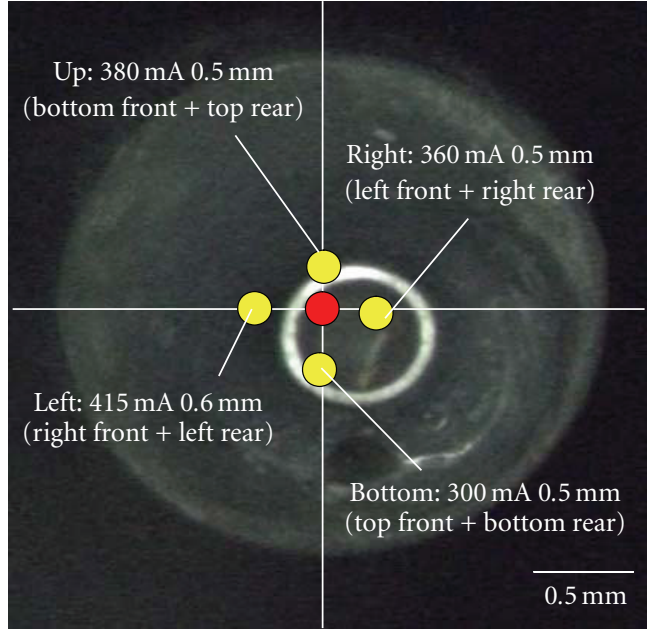

(a)

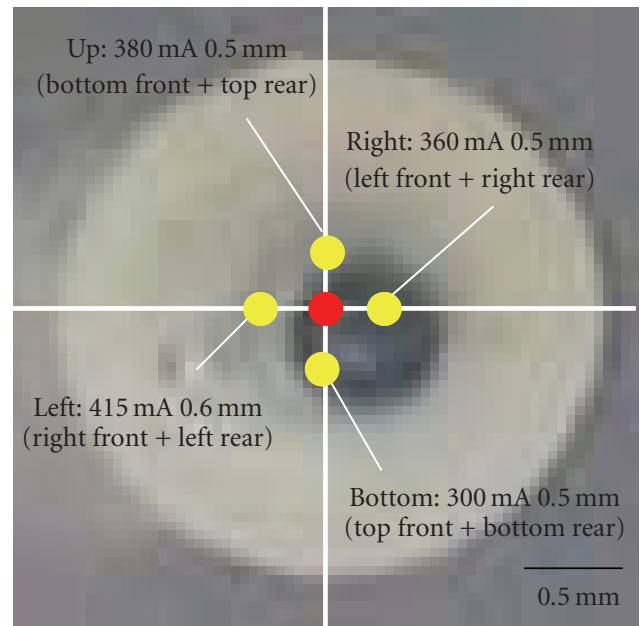

(b)

FIgURE 10: Actuation test results conducted in (a) room air temperature and (b) warm water at $310 \mathrm{~K}$. The applied current to the several actuators was controlled to move the catheter tip around $0.5 \mathrm{~mm}$.

\section{Conclusion}

We have designed and developed the forward-looking active catheter for the observation of a diseased area in a blood vessel. We have firstly formed Ti-Ni SMA spring actuators by electrochemical etching. The fabricated spring actuator could be driven by electrical heating, and it could generate a force enough to bend the catheter tube. The forward-looking active catheter having eight actuators and a transducer was produced. The parallel motion in the catheter tip was achieved by applying a certain current to a pair of actuators. The catheter tip moved in several intended directions by Joule's heating, and the drive distance was controlled by current value. We confirmed that the forward image was obtainable with the developed catheter using a fiberscope. The tip motions in warm water were verified to be almost the same as those in room air temperature. The developed catheter would be useful for the accurate and expeditious remedy in a blood vessel. 


\section{Acknowledgment}

The authors would like to thank members of New Business Department, Kobe Material Testing Laboratory, for fruitful discussion on this study.

\section{References}

[1] Y. Haga and M. Esashi, "Biomedical microsystems for minimally invasive diagnosis and treatment," Proceedings of the IEEE, vol. 92, no. 1, pp. 98-114, 2004.

[2] K. L. Gentry and S. W. Smith, "Integrated catheter for 3D intracardiac echocardiography and ultrasound ablation," IEEE Transactions on Ultrasonics, Ferroelectrics, and Frequency Control, vol. 51, no. 7, pp. 800-808, 2004.

[3] T. Mineta, T. Mitsui, Y. Watanabe, S. Kobayashi, Y. Haga, and M. Esashi, "An active guide wire with shape memory alloy bending actuator fabricated by room temperature process," Sensors and Actuators A, vol. 97-98, pp. 632-637, 2002.

[4] Y. Haga, T. Mineta, K. Totsu, W. Makishi, and M. Esashi, "Development of active catheter, active guide wire and micro sensor systems," Interventional Neuroradiology, vol. 7, no. 1, pp. 125-130, 2001.

[5] H. Kubo, M. Abe, T. Mineta, E. Makino, and T. Shibata, "Fabrication of microactuator for active catheter from SMA thin film tube," in Proceedings of the 21st Sensor Symposium, pp. 39-42, 2004.

[6] S. Sethuraman, S. R. Aglyamov, J. H. Amirian, R. W. Smalling, and S. Y. Emelianov, "Intravascular photoacoustic imaging using an IVUS imaging catheter," IEEE Transactions on Ultrasonics, Ferroelectrics, and Frequency Control, vol. 54, no. 5, pp. 976-986, 2007.

[7] R. H. Wolf and A. H. Heuer, "TiNi (shape memory) films on silicon for MEMS applications," Journal of Microelectromechanical Systems, vol. 4, no. 4, pp. 206-212, 1995.

[8] E. Makino, M. Uenoyama, and T. Shibata, "Flash evaporation of TiNi shape memory thin film for microactuators," Sensors and Actuators A, vol. 71, no. 3, pp. 187-192, 1998.

[9] X. U. Huang and Y. Liu, "Substrate-induced stress and the transformation behavior of sputter-deposited NiTi thin films," Materials Science and Engineering A, vol. 352, no. 1-2, pp. 314$317,2003$.

[10] T. Mineta, "Electrochemical etching of a shape memory alloy using new electrolyte solutions," Journal of Micromechanics and Microengineering, vol. 14, no. 1, pp. 76-80, 2004.

[11] S. Miyazaki and A. Ishida, "Shape memory characteristics of sputter-deposited Ti-Ni thin films," Materials Transactions, JIM, vol. 35, no. 1, pp. 14-19, 1994.

[12] XU. Huang and Y. Liu, "Substrate-induced stress and the transformation behavior of sputter-deposited NiTi thin films," Materials Science and Engineering A, vol. 352, no. 1-2, pp. 314317, 2003.

[13] T. Namazu, Y. Tashiro, and S. Inoue, "Ti-Ni shape memory alloy film-actuated microstructures for a MEMS probe card," Journal of Micromechanics and Microengineering, vol. 17, no. 1, pp. 154-162, 2007.

[14] M. Komatsubara, T. Namazu, H. Nagasawa, T. Miki, T. Tsurui, and S. Inoue, "Development of the forward-looking active micro catheter actuated by ti-ni shape memory alloy springs," in Proceedings of the 22nd IEEE International Conference on Micro Electro Mechanical Systems (MEMS '09), pp. 1055-1058, January 2009.
[15] S. Inoue, T. Namazu, A. Hirayama, and K. Koterazawa, "Joule's heat induced shape memory behavior of Ti-Ni shape memory alloy thin films," Transactions of The Materials Research Society of Japan, vol. 29, no. 7, pp. 2985-2988, 2004.

[16] S. Inoue, K. Hori, N. Sawada, N. Nakamoto, and T. Namazu, "Shape memory behavior of Ti-Ni-X $(\mathrm{X}=\mathrm{Pd}, \mathrm{Cu})$ ternary alloy thin films prepared by triple-source DC magnetron sputtering," Materials Science Forum, vol. 638-642, pp. 20682073, 2010. 

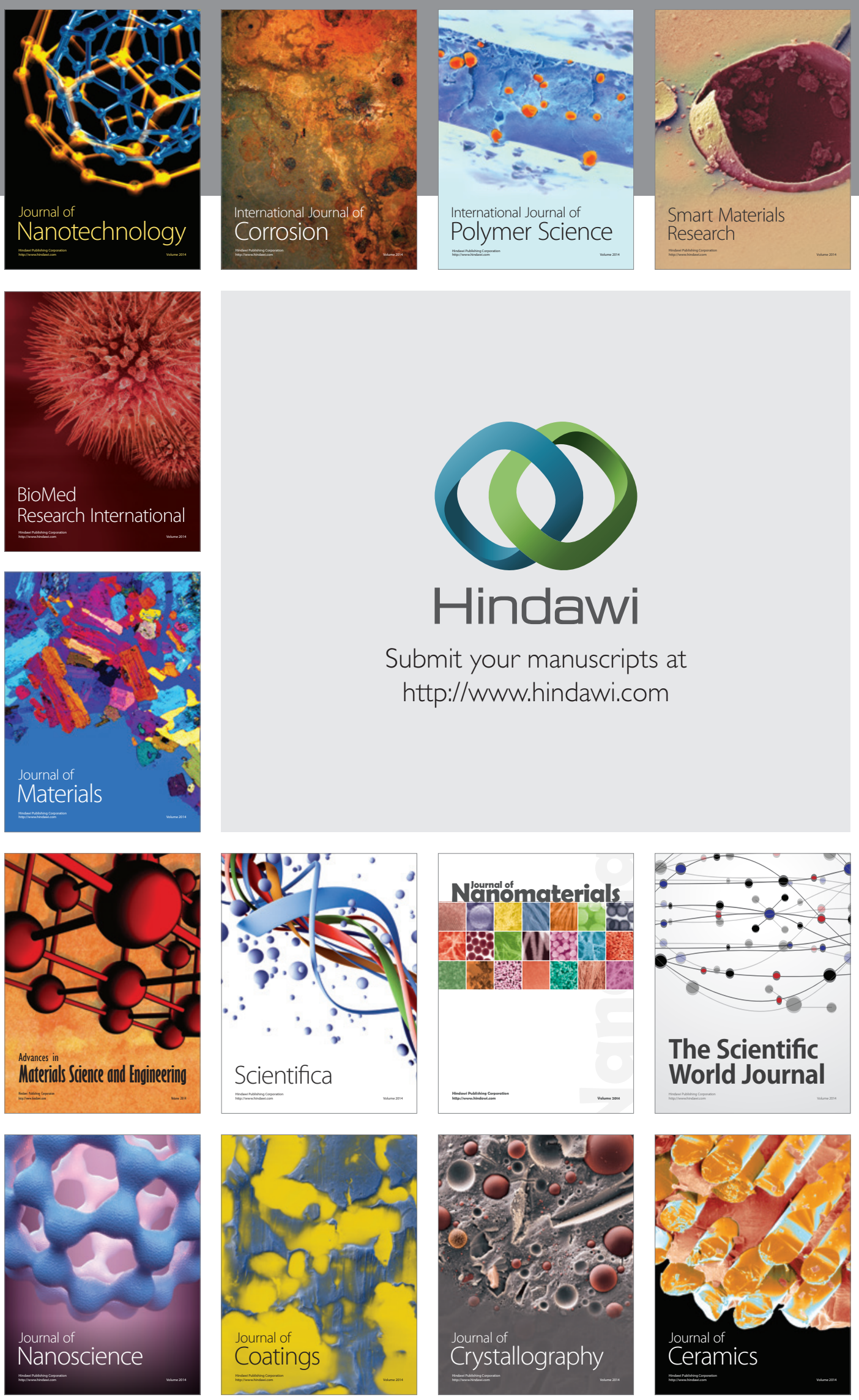

The Scientific World Journal

Submit your manuscripts at

http://www.hindawi.com

\section{World Journal}

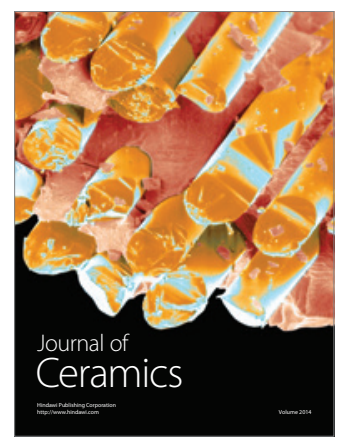

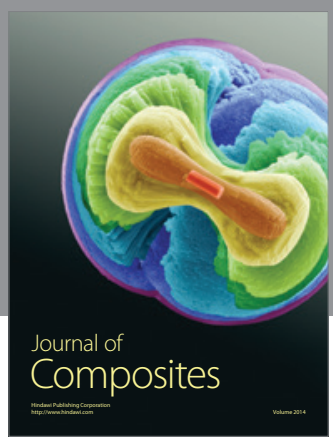
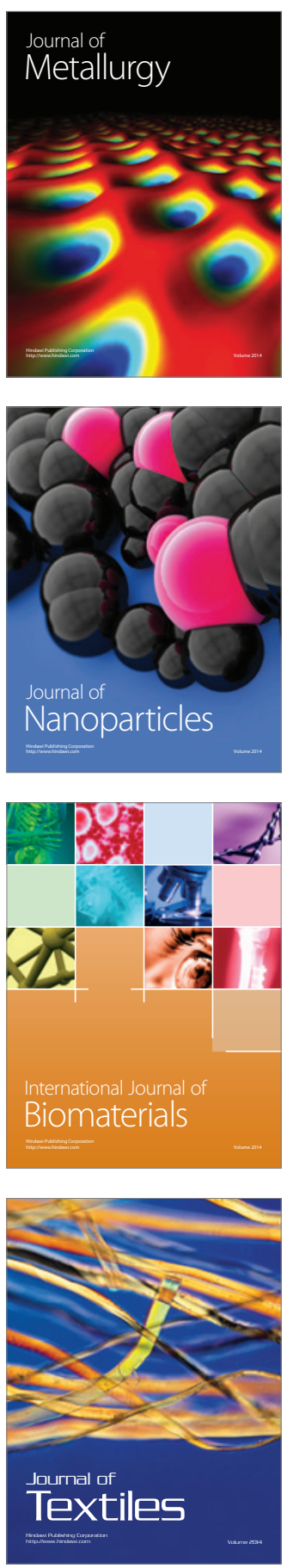